Note: This is a pre-copy-editing, author-produced PDF of an article accepted for publication in British Journal of Addiction following peer review. The definitive publisher-authenticated version [Parfrey PS (1977) Factors associated with undergraduate marijuana use in Cork, British Journal of Addiction, 72, 5965 ] is available online at http://www3.interscience.wiley.com/journal/117967480/toc

\title{
Factors Associated with Undergraduate Marijuana Use in Cork
}

\author{
P. S. Parfrey \\ Published in: British Journal of Addiction, 72 (1977), pp. 59-65 \\ Copyright: Wiley-Blackwell
}

\begin{abstract}
Summary
To examine cigarette, alcohol and drug use among undergraduates in University College, Cork a precoded questionnaire was mailed to 1 in 7 (458) students, chosen systematically. The response rate was 97 per cent. Twenty-three per cent of males and 13 per cent of females have taken marijuana at least once. Student use of marijuana was significantly related to leisure money available, belief in a God, frequency of attendance at religious services, attitudes to marriage partner drinking and to misdemeanour considered most serious. It appears that peer group pressures as illustrated by friends' drug taking, siblings' drug taking, encouragement by friends to take drugs and faculty, had a greater influence on student marijuana use than family related factors. Current cigarette use, pattern of drinking behaviour, use of other drugs and attitude to future marijuana use also had significant associations with marihuana-related behaviour.
\end{abstract}

\section{Introduction}

Abuse of drugs and the development of drug dependence are not new problems in Ireland, but in the past the people involved were relatively few in number and largely confined to special categories (Working Party on Drug Abuse. 1971). In the 1960's there has been a change in the Western World from the old traditional type of middle-aged, middle class drug addict to the younger addict (W.H.O., 1973). Drugs traditionally used only in certain parts of the world are becoming popular elsewhere and there is also a trend towards multiple drug use by the same person.

Estimates of the prevalence of drug use in Ireland, and particularly in Irish Universities, have been few-a fact noted by the Working Party on Drug Abuse (1971). Recent surveys of drug use among Glasgow University medical students (McKay, Hawthorne and McCartney, 1973) and of cannabis use amongst British University students (Kosviner, Hawks and Webb, 1973) suggest that drug abuse is not inconsiderable. Ireland is unlikely to escape such influences and therefore a study was undertaken in University College Cork to investigate the extent and prevalence of intoxicant (drugs, alcohol, and cigarettes) use among undergraduates, and to consider some of the sociological, behavioural and personality factors associated with intoxicant use.

\section{Method}

To examine cigarette, alcohol and drug use among undergraduates in Cork a precoded questionnaire was devised and mailed to 1 in 7 students, giving a sample of 458 . The population in the survey amounted to 3207 students, having a male : female ratio of $3: 2$. Only 2.5 per cent of the population were married and it was predominantly Catholic (90 per cent). The sample was chosen systematically from student class lists of names in alphabetical order, stratified into faculties. The response rate to the questionnaire was 97 per cent -444 out of 458 students returning the completed forms. Any minor discrepancy in the subsequent figures is due to incomplete answering of the questionnaire. The questionnaires were mailed in March 1973 and two subsequent follow-ups ensured the high response rate.

The questionnaire was divided into 3 parts and contained 53 questions. The first part explored the respondent's personality and socio-cultural background, including some questions on cigarette use. The second part was concerned with respondent's experience of and attitudes to alcohol, while the final part examined the student's drug taking experiences. Logical consistency checks confirmed the validity of the 
data, which was analysed by computer, following editing for accuracy and uniformity. The chi-squared test was the main test of significance.

The results presented in this paper refer only to student drug-related behaviour, and particularly to marijuana related behaviour, as marijuana was the drug most frequently used. The factors analysed include (i) demography; (ii) family; (iii) peers; (iv) personality; (v) moral and religious behaviour; (vi) intoxicant related behaviour.

\section{Results}

\section{Demographic Factors}

Sex: The analyses are based on the replies from 264 male and 178 female students who completed the questionnaires. Twenty-three per cent of males and 13 per cent of females have taken marijuana at least once and much smaller percentages have taken L.S.D. or barbiturates or amphetamines at least once (Table 1). Nobody admitted to having taken heroin or some other hard drug. Three per cent of males (7) and 1 female admitted to taking marijuana regularly and 1 male admitted to taking L.S.D. regularly. Nearly a third (21) of males and half (11) the females who had taken marijuana had no second occasion of drug use.

Age: Sixteen per cent (25) of males aged 17-20 years had taken marijuana compared with 32 per cent (35) of males aged 20 years or older $\left(x^{2}=8.84, p<0.005\right)$. Among females aged 17-20 years 10 per cent (13) had taken marijuana, compared with 23 per cent (10) of those aged 20 years or older $\left(x^{2}=4.24, p<0.05\right)$.

\section{Family Factors}

Higher percentages of students who had taken marijuana considered serious family conflict occurred quite frequently, compared with those who had no experience of marijuana but the association was not significant. Other family factors, such as mother or father dead or absent from the age of 12 years onwards, place of abode during term, parental use of sedatives, cigarettes or alcohol, and social class were not significantly related to undergraduate marijuana use.

Table 1. Drug taken at least once

\begin{tabular}{lcccccc}
\hline & \multicolumn{2}{c}{ Male } & \multicolumn{2}{c}{ Female } & \multicolumn{2}{c}{ Total } \\
& $\mathrm{N}$ & $\%$ & $\mathrm{~N}$ & $\%$ & $\mathrm{~N}$ & $\%$ \\
\cline { 2 - 7 } Marijuana & 60 & 23 & 23 & 13 & 83 & 19 \\
L.S.D. & 8 & 3 & 5 & 3 & 13 & 3 \\
Barbiturates or amphetamines & 11 & 4 & 3 & 2 & 14 & 3 \\
\hline Sample response & 264 & 100 & 178 & 100 & 442 & 100 \\
\hline
\end{tabular}

Leisure Money Available

Seventy-five per cent (45) of males who have taken marijuana, spend $£ 3$ or more a week on items other than board and lodgings compared with 52 per cent (104) of males who have never taken marijuana $\left(\mathrm{x}^{2}=\right.$ 9.28. $\mathrm{p}<0.005)$. Among females the association between marijuana use and leisure money available was also significant $\left(\mathrm{x}^{2}=4.78, \mathrm{p}<0.05\right)$. In fact, 52 per cent (12) of females who have taken marijuana spend $£ 3$ or more a week on items other than board and lodgings, compared with 27 per cent (41) of females who have never taken marijuana.

In an endeavour to discover whether marijuana use was related to parental indulgence the relationship between marijuana use and leisure money available was analysed while controlling for social class. Students social class was derived from father's or guardian's occupation utilizing the Registrar General's Classification of Occupations (1970). Among students in Social Class 1 or 2, 71 per cent (40) of those who had used marijuana spend $£ 3$ or more a week on items other than board or lodgings in comparison with 41 per cent $(99)$ of those who had never taken the drug $\left(X^{2}=15.82, p<0.001\right)$. The association was not significant when analysing students in social classes 3,4 or $5(\mathrm{p}<0.2)$. 
Drug taking by Friends: Strong peer group pressures which appeared to influence student marijuana use were evident. Two-thirds (40) of males with experience of marijuana had friends who had taken drugs, compared with just over a quarter (54) of males who had no experience of marijuana $\left(\mathrm{x}^{2}=30.94, \mathrm{p}<\right.$ 0.001). This association was equally significant among females, as 74 per cent (17) of females who had used marijuana and, in comparison 21 per cent (32) who had not used marijuana had friends who had taken drugs $\left(\mathrm{x}^{2}=25.88, \mathrm{p}<0.001\right)$.

Drug taking by Sibling(s): Although 38 students had brothers and/or sisters who had taken drugs the relationships between sibling drug use and student marijuana use were positive. Among males, 22 per cent (13) of those who had taken marijuana had sibling(s) who had used drugs, compared with 4 per cent (9) of those who had never taken marijuana $\left(x^{2}=15.88, p<0.001\right)$. Among females 35 percent $(8)$ of those who had experience of marijuana had sibling(s) who had taken drugs, compared with 5 per cent (8) of those who had no experience of marijuana $\left(x^{2}=18.01, p<0.01\right)$.

Encouragement by Friends: Seventeen per cent (46) of males and 10 per cent (17) of females felt they had been encouraged by their friends 10 take drugs. The associations between marijuana use and encouragement by friends to take drugs were highly significant for both males and females. Forty per cent (24) of males with experience of marijuana considered they had been encouraged to take drugs by their friends, whereas 11 per cent (22) of males without experience of marijuana were of this opinion $\left(\mathrm{x}^{2}=\right.$ $25.51, \mathrm{p}<0.001)$.

Among females, 39 per cent (9) of those who had taken marijuana fell they had been encouraged by their friends to take drugs, compared with 5 per cent (8) of those who had never taken marijuana $\left(x^{2}=22.97, p\right.$ $<0.001)$.

Faculty: Although the number of students in each category may be small Table 2 shows that following standardization for sex, a higher than expected number of Commerce and Law students and a lower than expected number of Science and Dairy Science students have taken marijuana. The associations between marijuana use, examination standard and future aspirations in life were not significant.

Table 2. Marijuana use related to faculty, following standardisation for sex

\begin{tabular}{|c|c|c|c|c|c|}
\hline $\begin{array}{l}\text { Have taken } \\
\text { Marijuana }\end{array}$ & Arts & Medicine & Engineering & $\begin{array}{c}\text { Science and } \\
\text { Dairy Science }\end{array}$ & $\begin{array}{c}\text { Commerce } \\
\text { and Law }\end{array}$ \\
\hline Observed & 28 & 13 & 15 & 4 & 23 \\
\hline Expected & 28 & 16 & 12 & 13 & 11 \\
\hline 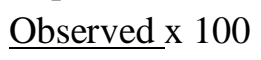 & 100 & 81 & 125 & 31 & 209 \\
\hline Expected & & & & & \\
\hline
\end{tabular}

\section{Moral and Religious Factors}

Belief in a God: In this sample 84 per cent (220) of males and 94 per cent (165) of females believed in a God. Seventy per cent (41) of males and 82 per cent (18) of females who had taken marijuana believed in a God, compared with 88 per cent (179) of males and 96 per cent (147) of females who had never taken marijuana $\left(\mathrm{x}^{2}=9.85, \mathrm{p}<0.002\right.$ for males and $\mathrm{x}^{2}=4, \mathrm{p}<0.05$ for females $)$.

Attendance at Religious Services: The negative association between those who had taken drugs and religion is further illustrated by the finding that a relatively low proportion (41 per cent) of males who had taken drugs attended religious services once or more than once a week compared with males ( 90 per cent) who had no experience of marijuana $\left(\mathrm{x}^{2}=62.37, \mathrm{p}<0.001\right)$. A similar association was observed with females. Seventy per cent (16) of females who had used marijuana, compared with 94 per cent (144) of those who had not, went to religious services once or more than once a week $\left(x^{2}=10.6, p<0.002\right)$. 
Attitude to Marriage Partner Drinking: Polarization was observed on analysis of students attitudes to the opposite sex drinking. This polarization of attitudes was associated with marijuana use. Three per cent (2) of males who had experience of marijuana would prefer to marry a teetotaller; 50 per cent (30) would prefer to marry a social drinker and 47 per cent (28) considered the question immaterial. This contrasted with the males who had never taken marijuana, 21 per cent (43) of whom would prefer to marry a teetotaller, 39 per cent (80) would prefer to marry a social drinker and 39 per cent (80) thought the question immaterial $\left(\mathrm{x}^{2}=10.46, \mathrm{p}<0.01\right)$. Among females who had taken marijuana none would prefer to marry a teetotaller, 57 per cent (13) would prefer to marry a social drinker, and the remaining 10 females thought the question immaterial. This finding, as in males, contrasted with the females who had never used marijuana-23 per cent (35) would prefer a teetotaller as marriage partner, 51 per cent (77) a social drinker, and the remainder 26 per cent (40) thought it immaterial $\left(x^{2}=7.49, \mathrm{p}<0.05\right)$.

Misdemeanour Considered mast Serious: Students were questioned concerning their attitude to getting drunk, having extra-marital sexual intercourse and cheating at examinations. Forty-five per cent (114) of males considered having sexual intercourse outside marriage more serious than cheating at examinations or than getting drunk, whereas 47 per cent considered cheating at examinations most serious. However, analysis of these attitudes among male users and nonusers of marijuana demonstrated no significant relationship. Among females the relationship was significant $\left(x^{2}=18.15, p<0.001\right)$. Among females who had taken marijuana 4 per cent (1) considered getting drunk most serious, 17 per cent (4) considered having extra-marital intercourse most serious and 78 per cent (18) felt cheating at examinations was most serious. This contrasted with the females who had no experience of the drug, in that 8 per cent (12) felt getting drunk as the most serious misdemeanour, 60 per cent (88) considered extra-marital intercourse as the most serious and the remainder (47) endorsed cheating at examinations.

Significant associations were not obtained on relating marijuana use to active participation in sport, university societies, or political organizations.

\section{Intoxicant Use}

Smoking Cigarettes: Students who had used marijuana were much more likely to smoke cigarettes than non-users. Among males who had taken marijuana 52 per cent (28) smoked compared with 31 per cent (63) among those who had never taken marijuana $\left(\mathrm{x}^{2}=7.84, \mathrm{p}<0.001\right)$. Among females with experience of marijuana 57 per cent (13) smoked compared with 23 per cent (36) of females who had no experience of marijuana $\left(\mathrm{x}^{2}=9.52, \mathrm{p}<0.005\right)$.

Alcohol Use: A similar pattern emerges for alcohol use. All males and females who had used marijuana drank, compared with 74 per cent (148) of males and 59 per cent (90) of females who had never used marijuana. Furthermore, users of marijuana were more likely to be in the heavier drinking categories. Sixty-nine per cent (40) of males and 48 per cent (11) of females who had taken marijuana either did not limit consumption of alcohol and did not drink to drunkenness (social drinker) or indulged in short periods of drinking to drunkenness at sporadic intervals (occasional drunk). This contrasted with the students who had never taken marijuana -49 per cent (98) of males and 13 per cent (20) of females who had never taken marijuana admitted to being social drinkers or occasional drunks $\left(x^{2}=19.39, p<0.001\right.$ for males; $\mathrm{x}^{2}=23.36, \mathrm{p}<0.001$ for females).

Use of Other Drugs: As expected use of L.S.D. or barbiturates or amphetamines was significantly associated with marijuana use. In fact all 13 students who had taken L.S.D. at least once and 11 of the 14 students who had taken barbiturates or amphetamines for non-medical reasons had experience of marijuana.

Attitude to Future Marijuana Use: Not surprisingly students who had taken marijuana were more likely to consider that they would take marijuana in the future if the opportunity arose. Sixty-eight per cent (41) of males and 57 per cent (13) of females who had taken marijuana would take marijuana if the opportunity arose, compared with 19 per cent (39) of males and 11 per cent (17) of females who had never used marijuana $\left(\mathrm{x}^{2}=50.87, \mathrm{p}<0.001\right.$ for males; $\mathrm{x}^{2}=2.65, \mathrm{p}<0.001$ for females $)$. 


\section{Discussion}

Kosviner and Hawks (1973) considered it profitable to abandon notions of simple causal links between certain psychosocial variables and cannabis use, and instead to view any such associations as indicative of a general style of behaviour or orientation, with cannabis use only one possible feature of this general style.

The present study showed that students who had taken marijuana at least once appeared to have more leisure money available, were likely not to believe in a God and also to have a less frequent attendance at religious services, tended to have a polarized altitude to the opposite sex drinking, were probably smoking and drinking and also more prone to get drunk and were more likely to progress to further use of hallucinogens, than the students who had never taken marijuana. Although not involving the concept of the "bohemian student" (Young and Crutchley 1972) these associations with marijuana use suggest that individuals who have taken marijuana tend to prefer an unstructured and liberal lifestyle, value stales of altered consciousness, and tend to seek such effects through intoxicant use.

Drug use is often associated with powerful socio-cultural forces such as friendship, peer group approval and pressures and local customs (W.H.O., 1973). In the Cork study, peer group pressures are evident from analysis of drug taking by friends and siblings and from data on students encouraged to take drugs by friends.

In a study of cannabis use among British university students Kosviner and Hawks (1973) tentatively suggested that a pattern emerges from their data that could broadly be seen in terms of users displaying looser association with traditional transmitters of societal morality. In the present study such a pattern does not emerge as judged from the lack of significant associations between marijuana use and frequency of family conflict, parental use of intoxicants, place of abode during term and social class. However, availability of leisure money was an important factor in marijuana use although parental indulgence, indirectly detected by relating leisure money available to marijuana use when controlling for social class, was a less important factor.

Jessor, Graves, Hanson and Jessor (1968) have suggested that drug users would be more likely to question conventional goals or pay-offs and instead start thinking in terms of other options. The present analysis does not support this hypothesis, as the associations between examination success, future aspirations and marijuana use were not significant. However, girls who had taken marijuana (although few in number) tended to have a less traditional attitude to the question concerning the relative seriousness of getting drunk, having extra-marital intercourse or cheating at examinations. The trend among these girls was away from the traditional view of extramarital intercourse as the most serious misdemeanour towards a code which considers cheating at examinations more serious than getting drunk or having extra-marital intercourse. They may believe that honesty and sincerity are more important than traditional taboos. Furthermore this liberal trend was illustrated by the attitude of students, who had taken marijuana, towards drinking by their partner of the opposite sex. In this instance these students differed from the group who had never taken marijuana in that they did not prefer their marriage partner or boy/girl friend to be a teetotaller.

The hypothesis that marijuana users were among those deviants who reject societal norms with a clear alternative in mind (Merton, 1957) was tested by analysis of students active in political organizations, community societies and university societies. No distinct relationship was observed to support this hypothesis.

However, consistent differences were obtained between males and females who had taken marijuana and those who had never done so following analysis of student use of other intoxicants. Highly significant associations were obtained between marijuana use and use of alcohol, cigarettes and other intoxicants. Riesman (1969) has described the changes that have taken place in human thinking, from the "tradition directed" or authoritarian type of thought and behaviour to an "other directed type" of behaviour which is influenced by that of one's friends and associates. There is a third type of person who is "inner directed", whose behaviour is influenced by morals, who makes his own decisions about his beliefs according to his 
inner convictions. One may suggest from the present study that perhaps use of intoxicants is related to the "other directed" type of behaviour, and that this intoxicant related behaviour is influenced more significantly by friends and peer groups and is accompanied by a trend away from traditional, moral and religious beliefs and practices.

\section{Acknowledgements}

I thank Professor J. P. Corridan, Professor of Social and Preventive Medicine in University College, Cork for the supervision, patience and criticisms he offered throughout the project. I wish to thank Dr. T. M. F. O'Donovan, of the Department of Statistics, the staffs of the Computer Science and the various academic and administrative departments who gave their assistance. Finally thanks are due to my student colleagues without whose response the project would never have been completed.

\section{References}

JESSOR, R., GRAVES. T. D., HANSON, R. C. and JESSOR, S. L. (1968). Society Personality and Deviant Behaviour. Holt, Rinehart and Winston, New York.

KOSVINER, A., HAWKS, D. and WEBB, M. G. T. (1973). Cannabis use amongst British University students, Brit. J. Addict. 69, 35-60.

McKAY, A., J., HAWTHORNE, V. M. and McCARTNEY, H. N. (1973). Drug taking among medical students in Glasgow University, Brit. Med. J. 1, 540-543.

MERTON, R. K. (1957). Social Theory and Social Structure. Free Press, London.

REGISTRAR GENERAL'S CLASSIFICATION OF OCCUPATIONS (1970). H.M.S.O., London.

RIESMAN, D., GLAZER, N. and DENNEY, R. (1969). The Lonely Crowd. A study of the Changing American Character. New Haven and London, Yale University Press.

WORKING PARTY ON DRUG ABUSE, Report to the Minister of Health (1971). Dublin Stationery Office.

WRLD. HLTH. ORG. TECHN. REP. SER. YOUTH AND DRUGS (1973). p. 516.

YOUNG, J. and CRUTCHLEY, J. B. (1972). Student drug use. Drugs and Society October. 